\title{
Post Vaccination Titers of Serum Anti-Diphtheria in Indonesian Young and Middle- Aged Adults
}

Running tittle: diphtheria vaccination in ageing adults

Gatot Soegiarto $^{1 *}$, Diksi Novritasari ${ }^{2}$, Ari Baskoro ${ }^{1}$, Deasy Fetarayani ${ }^{1}$, Wita Kartika Nurani ${ }^{1}$

${ }^{1}$ Division of Allergy and Clinical Immunology, Department of Internal Medicine, Faculty of Medicine, Universitas Airlangga - Dr. Soetomo General Academic Hospital, Surabaya, Indonesia

2 Department of Internal Medicine, Faculty of Medicine, Universitas Airlangga - Dr. Soetomo General Academic Hospital, Surabaya, Indonesia

*Corresponding author: Gatot Soegiarto

Division of Allergy and Clinical Immunology, Department of Internal Medicine, Faculty of Medicine, Universitas Airlangga - Dr. Soetomo General Academic Hospital, Jl. Mayjend Prof. Dr. Moestopo No. 6-8, Airlangga, Gubeng, Surabaya, East Java 60286, Indonesia.

Phone: +6231-5036047

Email: gatot_soegiarto@fk.unair.ac.id

ORCID ID: 0000-0002-9197-3873

\section{Abstract}

Objective: This study aimed to evaluate the antibody responses in two adult age groups after diphtheria vaccination.

Study Design: An observational analytic study was carried out to determine the difference in serum titer of anti-diphtheria antibody.

Methods: Serum antibody titers were measured just before and 3 months after injection of Diphtheria toxoid vaccine. Vaccine was given to two adult age groups of health care personnel in hospital: the young ( $<40$ years) and the middle-aged ( $\geq 40$ years). Data were analyzed using the Mann-Whitney test $(p<0.05)$.

Results: Significant increase in serum anti-diphtheria antibody titers were recorded after vaccination in both age group ( $p<0.001$ in young adult and $p=0.001$ in middle-aged adult, respectively). There were no substantial differences between the two groups in terms of antibody titer before vaccination $(p=0.741), 3$ months after vaccination $(p=0.317)$ and in the increase of antibody titer $(p=0.479)$.

Conclusions: This study showed that there was no significant difference in the increase of anti-diphtheria antibody titers between the two age groups, proving that both young and middle-aged adults had an equal immune response to a given diphtheria vaccine.

Keywords: Age, Antibody titers, Diphtheria, Immunosenescence, Vaccine 


\section{Introduction}

The process of aging is a physiological change that develops with age and leads to a progressive decline in all bodily functions. This process is influenced by the interaction of dynamic genetic and environmental factors $[1,2]$. Immunosenescence or a decline in immune function in aging population is characterized by high susceptibility to infection, high incidence of malignancy and autoimmune diseases, and low antibody response to vaccination [3-5]. Low antibody responses has been reported in several studies of vaccinations against influenza [6], pneumococcus [7], hepatitis A [8], herpes zoster [9], yellow fever [10], tickborne encephalitis, tetanus, pertussis and diphtheria $[11,12]$. The immunosenescence processes in human include decreased ability of neutrophil and macrophage for phagocytosis, decreased oxidative bursts, decreased antigen-presenting cells (APCs) function, and changes in cytokine and chemokine secretion. In terms of adaptive immune function deterioration, there were decreased naive $\mathrm{T}$ and $\mathrm{B}$ cells numbers, changes in $\mathrm{T}$ cell receptor (TCR) expression, as well as decreased ability of B cells to carry out antibody class switch recombination (CSR), and antibody production [13-15].

There was a diphtheria outbreak in Indonesia in 2017 [16]. Factors contributing to the outbreak include low infant immunization rate and booster coverage, low socioeconomic status, and many vulnerable adults as it's been more than 10 years since they got their last immunization [17]. One of the countermeasures that are recommended by the Ministry of Health of the Republic of Indonesia is the implementation of Outbreak Response Immunization (ORI) against diphtheria using Jerap Td vaccine produced by Biofarma Ltd, Indonesia (production code: 044316)[18]. To date, there are no data on differences in antibody responses to diphtheria ORI (Jerap Td) vaccination between the young and old age groups in Indonesia. Health care workers have a greater risk of contracting diphtheria than the general population because they have to take care of the patients who are hospitalized and are directly exposed to the source of infection. That is why WHO and the Indonesian government recommended that all health care workers (especially those caring for diphtheria patients) to get diptheria vaccination in the ORI program. The aim of this study was to measure and to compare the anti-diphtheria antibody titers between groups of young and middle-aged health care workers at hospital in Surabaya, Indonesia who participated in the diphtheria ORI program.

\section{Methods}

This is an observational analytic study. The inclusion criteria include health care workers aged 18-64 years old, receiving diphtheria vaccination in the ORI program, willing to participate in the study, and agreeing to sign the informed consent. Exclusion criteria include had diabetes mellitus, HIV infection, currenty or had a history of using corticosteroids within 1 month prior to participating in this study, and had received a diphtheria booster vaccine in the last 10 years. Based on the susceptibility to diphtheria in previous study [19], participants were then divided into two groups, namely those who aged under 40 years (representing the young adult group), and those aged 40-64 years (representing the middle-aged adult group). Using "Sample Size Determination in Health Studies" software version 2.0.21 (World Health Organization, Geneva, USA) and two population means data from Carson et al [20], in order to detect a difference of post vaccination anti-diphtheria antibody titers between the two age groups with an alpha of 0.05 and a power of $80 \%$, we needed a minimum of 11 participants in each group. In our Internal Medicine department, there were 45 residents and 30 senior staff, but only 22 residents and 18 senior staff were willing to participate in this study.

Response to the vaccination can be measured by in vivo or in vitro methods. The in vivo method is the gold standard, which measures the ability of antibodies to neutralize diphtheria toxin in experimental animals[21], but this method is very expensive. In vitro measurement 
methods include toxin binding inhibition assay (ToBI), ELISA, haemagglutination assay, and Vero cell testing. ToBI and ELISA measure toxin-specific antibodies in total but do not distinguish between neutralizing and non-neutralizing antibodies. Vero cell assay (VCA) has a high degree of correlation with the in vivo biological assay and is therefore recommended by WHO as an alternative to the in vivo assay method [21, 22]. We use the VCA method in this study. Blood was withdrawn from study participants before and 3 months after Jerap Td vaccination and sent to Laboratory Center for determination of IgG anti-diphtheria toxin antibody titers. Measurement were done using a standardized and calibrated instrument, and titers were expressed in IU/mL.

Specific antibody titers greater than $0.1 \mathrm{IU} / \mathrm{mL}$ are considered protective against tetanus or diphtheria, levels above $1.0 \mathrm{IU} / \mathrm{mL}$ are considered a sign of long-term protection, while titer of $0.01 \mathrm{IU} / \mathrm{mL}$ is considered as partial protection [23].

The normality of data distribution was assessed using Shapiro Wilk test. The MannWhitney test was used to determine the difference (delta) between two variables that were not normally distributed. Data were analyzed using the SPSS program for Windows version 23.0 (SPSS Inc., Chicago, IL, USA). This study was ethically approved by Health Research Ethics Committee of Hospital (0008/KEPK/I/2018).

\section{Results}

From January to July 2018, a total of 40 participants were willing to take part in this study and meet the inclusion and exclusion criteria. Twenty two participants were included in the young adult group category (aged $<40$ years), while 18 others were in the middle age adult group (aged $\geq 40-64$ years). The median age of the young adult group was 31 years (ranged: 26-39 years), while the median age of the middle-aged adult group was 46 years (ranged: $40-$ 64 years). We also tried to analyze the potential differences by grouping the participants into 4 groups of 10 year age band (i.e. < 30 years, 31-40 years, 41-50 years, and > 50 years). However, because we did not detect any significant differences in antibody titers between groups (data not shown), we prefer to use groupings based on the result of previous study by Völzke et al [23], i.e. using a cut-off age of 40 years. General characteristics of the study participants can be seen in Table 1 . There were 21 participants $(96 \%)$ from the young adult group who had been exposed to diphtheria patients when they were on duty, while only 7 participants $(39 \%)$ of the middle-aged adult group exprerienced the same circumstance. Nineteen participants $(86 \%)$ from the young adult group and 14 participants $(79 \%)$ from the middle-aged adult group had received the diphtheria vaccine in the past.

Table 1. General characteristics of study subjects

\begin{tabular}{lcc}
\hline \multicolumn{1}{c}{ Characteristics } & $\begin{array}{c}\text { Young adults } \\
(<40 \text { years old }) \\
\mathrm{n}=22\end{array}$ & $\begin{array}{c}\text { Middle-aged adults } \\
(\geq 40 \text { years old }) \\
\mathrm{n}=18\end{array}$ \\
\hline $\begin{array}{l}\text { Age (years) } \\
\text { Median (Min - Max) }\end{array}$ & $31(26-39)$ & $46(40-64)$ \\
Gender & $11(50 \%)$ & $10(56 \%)$ \\
$\quad$ Male (\%) & $11(50 \%)$ & $8(44 \%)$ \\
$\quad$ Female (\%) & $21(96 \%)$ & $7(39 \%)$ \\
Exposure to diphtheria patients & $1(4 \%)$ & $11(61 \%)$ \\
$\quad$ Ever (\%) & $19(86 \%)$ & $14(79 \%)$ \\
$\quad$ Never (\%) & $3(14 \%)$ & $4(21 \%)$ \\
Previous diphtheria vaccination &
\end{tabular}

Min = minimum; Max = Maximum. 
The data of $\mathrm{IgG}$ anti-diphtheria antibody titers showed an abnormal distribution. The median value of anti-diphtheria antibody titers before vaccination was $0.128 \mathrm{IU} / \mathrm{mL}$ (IQR $0.612 \mathrm{IU} / \mathrm{mL}$ ) in the young adult group and $0.256 \mathrm{IU} / \mathrm{mL}$ (IQR $2.032 \mathrm{IU} / \mathrm{mL}$ ) in the middleaged adult group. The median value of anti-diphtheria antibody titers 3 months after vaccination was $4.096 \mathrm{IU} / \mathrm{mL}$ (IQR $4.683 \mathrm{IU} / \mathrm{mL}$ ) in the young adult group and $3.072 \mathrm{IU} / \mathrm{mL}$ (IQR $3.840 \mathrm{IU} / \mathrm{mL}$ ) in the middle-aged adult group. So far no correlation was found between age and antibody titers ( $p>0.05$, Spearman correlation), and the rise in antibody titers ( $p=$ 0.368 , Wilcoxon Signed Ranks test; both data were not shown). Figure 1 and 2 showed that there were no significant difference between the two groups in terms of anti-diphtheria antibody titer before or 3 months after vaccination ( $p=0.741$ and $p=0.317$, respectively).

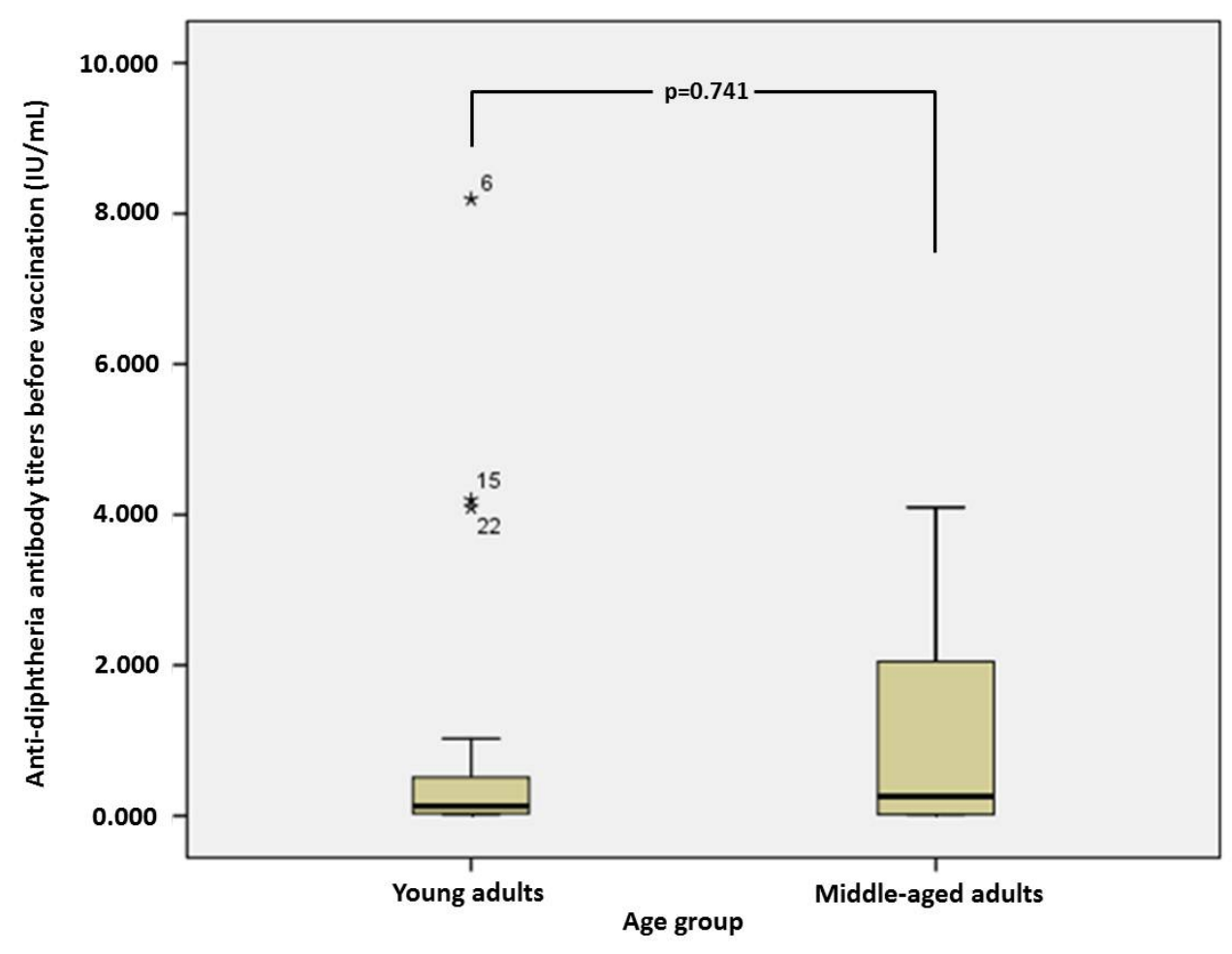

Figure 1. Anti-diphtheria antibody titers before vaccination in the young and the middle-aged adults. 


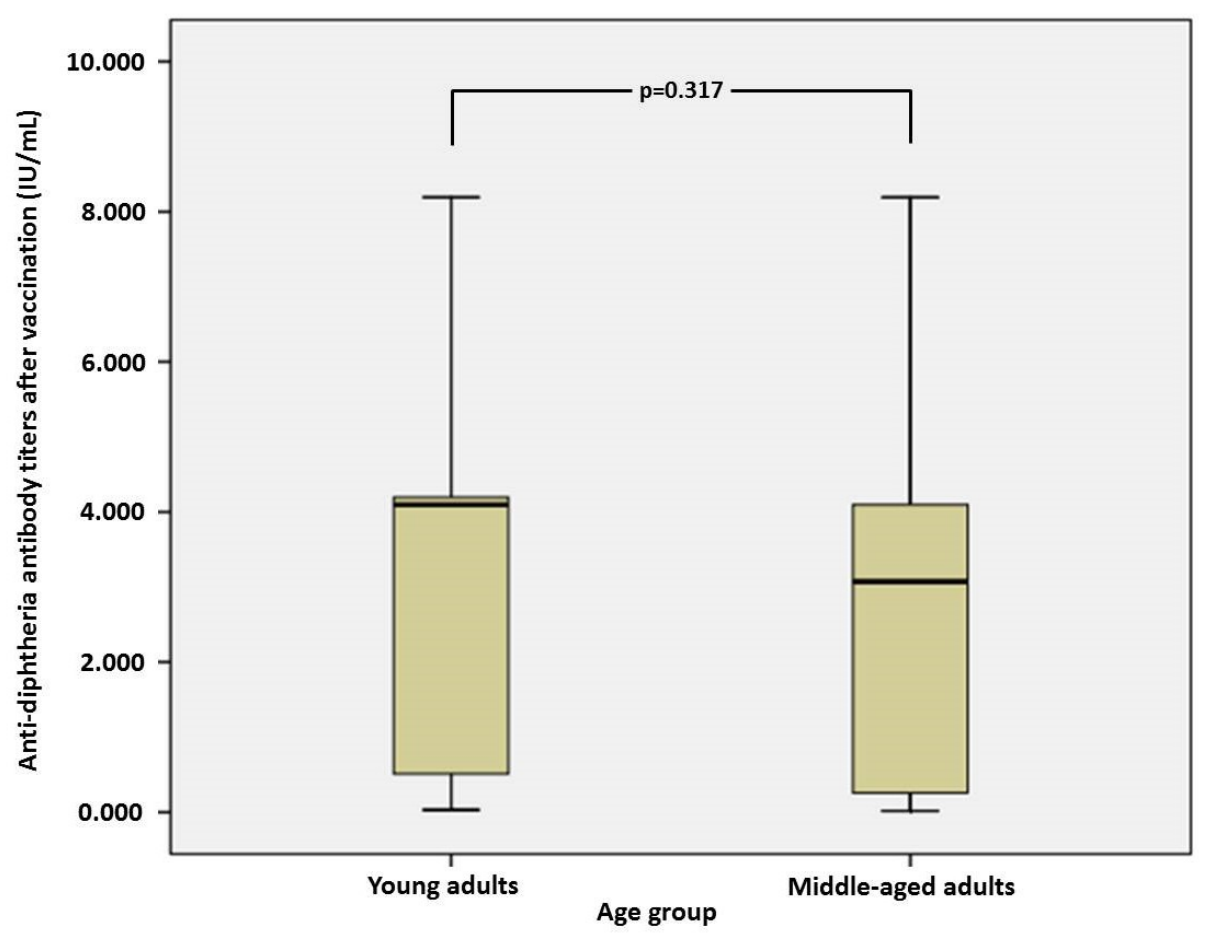

Figure 2. Anti-diphtheria antibody titers 3 months after vaccination in the young and the middle-aged adults.

Diphtheria vaccination with Jerap Td vaccine induced a significant increase in antidiphtheria antibody titers both in young and middle-aged adult group $(p<0.001$ and $p=$ 0.001 , respectively) as can be seen in Figure 3.

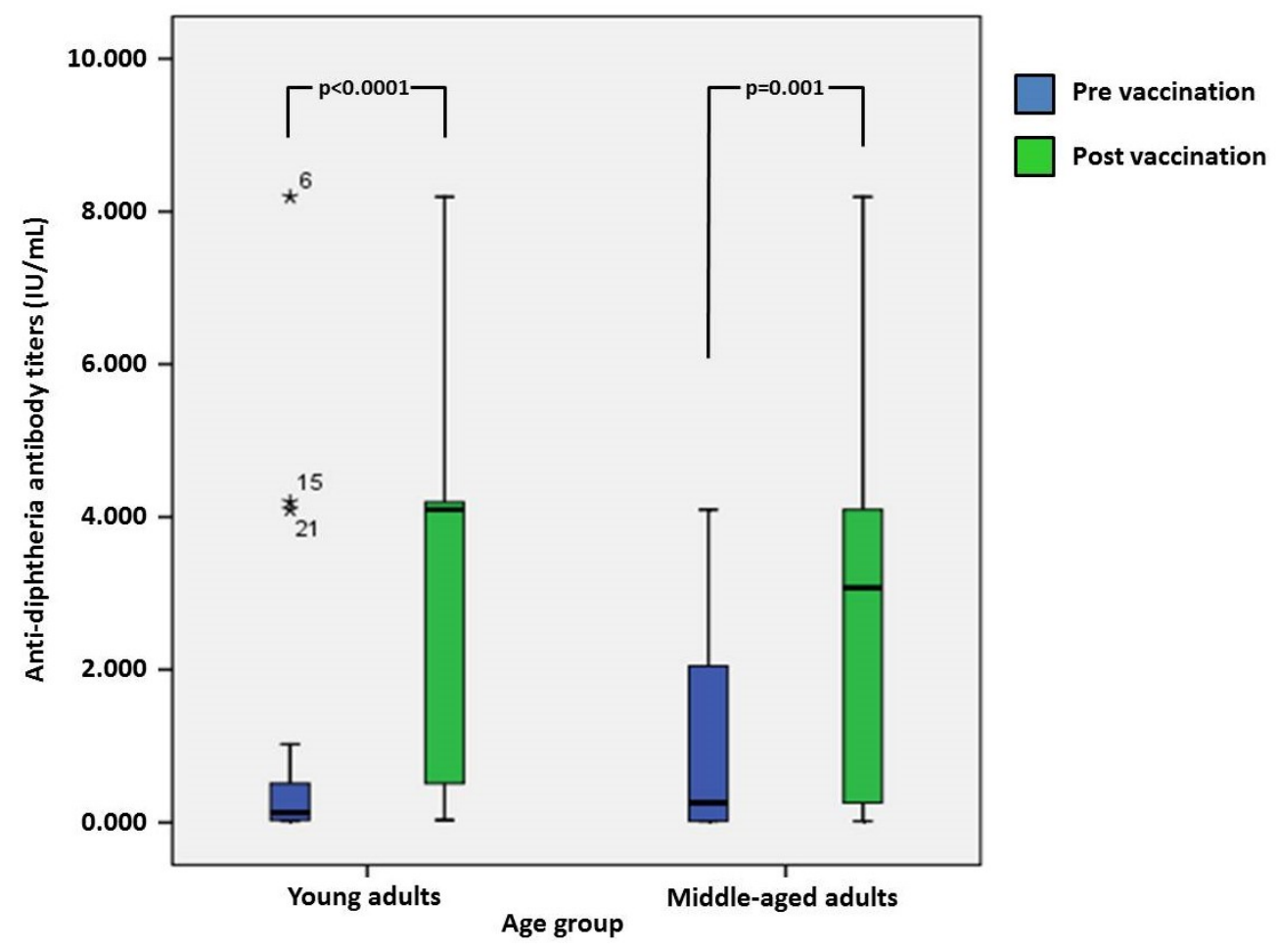

Figure 3. Comparative increase in anti-diphtheria antibody titers after vaccination in the young and the middle-aged adults 
Comparative tests for the differences of anti-diphtheria antibody titers between groups are listed in Table 2. Table 3 shows pre and post vaccination anti-diphtheria antibody titers in the young and the middle-aged adult groups based on levels of protection. Jerap Td vaccination induced a significant increase in anti-diphtheria antibody titers in both age group. The magnitude of the increase in antibody titer measured before and after vaccination (delta $=$ $\Delta$ ) also did not show a significant difference betwen the two groups ( $p=0.479$; MannWhitney test), suggesting that both young adult and middle-aged adult group had an equal response to the vaccine.

Table 2. Comparison of anti-diphtheria antibody titers before and 3 months after vaccination in the young and the middle-aged adult groups

\begin{tabular}{|c|c|c|c|}
\hline Vaccine & $\begin{array}{c}\text { Young adults } \\
(<40 \text { years old }) \\
n=22\end{array}$ & $\begin{array}{l}\text { Middle-aged adults } \\
\begin{array}{c}(\geq 40 \text { years old }) \\
n=18\end{array} \\
\end{array}$ & $\mathrm{p}$ \\
\hline $\begin{array}{l}\text { Anti-diphtheria antibody titers } \\
\text { before vaccination [Median, } \\
(\mathrm{IQR}) \text {, in } \mathrm{IU} / \mathrm{mL} \text { ] }\end{array}$ & $\begin{array}{c}0.128 \\
(0.612)\end{array}$ & $\begin{array}{c}0.256 \\
(2.032)\end{array}$ & $0.741^{*}$ \\
\hline $\begin{array}{l}\text { Anti-diphtheria antibody titers } \\
\text { after vaccination [Median, (IQR), } \\
\text { in } \mathrm{IU} / \mathrm{mL} \text { ] }\end{array}$ & $\begin{array}{c}4.096 \\
(4.683)\end{array}$ & $\begin{array}{c}3.072 \\
(3.840)\end{array}$ & $0.317^{*}$ \\
\hline $\begin{array}{l}\text { Delta anti-diphtheria antibody } \\
\text { titers before and after vaccination } \\
{[\text { Median, (IQR), in } \mathrm{IU} / \mathrm{mL}]}\end{array}$ & $\begin{array}{c}1.850 \\
(3.720)\end{array}$ & $\begin{array}{c}1.536 \\
(3.624)\end{array}$ & $0.479^{*}$ \\
\hline
\end{tabular}

* Mann-Whitney test for data with abnormal distribution.

Table 3. Pre and post vaccination anti-diphtheria antibody titers in the young and the middleaged adult groups based on levels of protection

\begin{tabular}{llccc}
\hline \multicolumn{1}{c}{$\begin{array}{c}\text { Antibody titer and } \\
\text { level of protection }\end{array}$} & $\begin{array}{c}\text { Young adults } \\
(<40 \text { years old }) \\
\mathrm{n}(\%)\end{array}$ & $\begin{array}{c}\text { Middle-aged adults } \\
(\geq 40 \text { years old }) \\
\mathrm{n}(\%)\end{array}$ & $\mathrm{p}$ \\
\hline $\begin{array}{l}\text { Pre vaccination } \\
<0.1 \mathrm{IU} / \mathrm{mL}\end{array}$ & low or partial protection & $10(45.45 \%)$ & $7(38.88 \%)$ & $0.424^{*}$ \\
$0.1-1.0 \mathrm{IU} / \mathrm{mL}$ & substantial protection & $7(31.81 \%)$ & $4(22.24 \%)$ & \\
$\geq 1.0 \mathrm{IU} / \mathrm{mL}$ & long-term protection & $5(22.74 \%)$ & $7(38.88 \%)$ & \\
\hline $\begin{array}{llll}\text { Post vaccination } \\
<0.1 \mathrm{IU} / \mathrm{mL}\end{array}$ & low or partial protection & $1(4.54 \%)$ & $2(11.10 \%)$ & $0.612^{*}$ \\
$0.1-1.0 \mathrm{IU} / \mathrm{mL}$ & substantial protection & $5(22.74 \%)$ & $4(22.24 \%)$ & \\
$\geq 1.0 \mathrm{IU} / \mathrm{mL}$ & long-term protection & $16(72.72 \%)$ & $12(66.66 \%)$ & \\
\hline
\end{tabular}

* Comparison between groups, Mann-Withney test

\section{Discussions}

When the diphtheria outbreak strike in Indonesia in 2017 and the Indonesian government responded by giving the ORI using Jerap Td vaccine (not only for high risk groups of the population but also for the health care personnel), we had the rare opportunity to compare the difference in diphtheria vaccine response between the young and the middle-aged adults. The human immune system undergoes characteristic changes, declines in function with advancing age, which termed immunosenescesnce [3]. This leads to an increased susceptibility to 
infection and associated with increased morbidity [4, 5]. Immunesenescence also has implications for vaccination programs. There is clear evidence that the decline in innate and adaptive immunity results in dramatically reduced vaccine responses and vaccine longevity in older adults. This phenomenon can be seen in many studies [6-11]. Based on the susceptibility to diphtheria in a previous study [19], we used 40 year of age as a cut-off point between young and middle-aged adults.

While there is a wide consensus that immune dysfunction occurs in old age, it is still not known at what age the immune system start to decline. Regarding the response to the vaccine, various conditions suggest different starting age for the decline in antibody titers after vaccination. Hainz et al. evaluated specific antibodies for tetanus toxoid or tick-borne encephalitis (TBE) virus in 734 adults (aged 18-93 years) and their relationship to the time point of the last vaccination against tetanus or TBE and the age. It appears that the declined immune response to vaccine was set at the age of 40 years in the case of tetanus and was observed right throughout adult life in the case of TBE [24]. Murphy et al found that immunity to diphtheria vaccine was lower than immunity to tetanus vaccine. From the data of the United States national population-based serosurvey that was conducted during 1988-1994 evaluating the prevalence of immunity to diphtheria among woman, he reported that the prevalence of immunity to diphtheria was also decreasing with age, being $77 \%$ among women aged $12-19$ years, $74 \%$ among women aged $20-29$ years, $65 \%$ among women aged 30-39 years, and drastically decreased to $<45 \%$ among women aged $>40$ years [25].

Other studies seem to explain the findings of Hainz et al [24] and Murphy et al[25], and indirectly support our decision to use 40 years of age as a cut-off point for age groups. Hakim et al [26] had assessed the role of thymic function after autologous transplant in adults in a long-term single cohort study. They concluded that the frequency of effective renewal of thymopoiesis declines significantly in patients over 40 years of age. Thus, the reduced thymic output together with a life-long exposure to antigens leads to a shrinkage of the naive T-cell pool in elderly persons $[27,28]$, which eventually lead to decreased B-cell help by T-cell, and decreased antibody production in response to vaccination $[29,30]$.

Our study yielded some findings. Firstly, $86 \%$ of the young adults and $79 \%$ of the middle-aged adults had received primary immunization in the past. This finding can be explained by the fact that annual mass vaccination programs such as in National Immunization Week (Pekan Imunisasi Nasional) in Indonesia have only been carried out routinely since the early 1990s. That is why more young adults get primary immunization. In this regard, Indonesia is a bit late compared to neiboring countries such as Korea [31] or India [32].

Secondly, although there was no significant difference, the middle-aged group had slightly lower titers of anti-diphtheria antibody before re-vaccination with ORI compared to the young adult group. Previous research by Launay et al, has found significant differences in anti-diphtheria toxin antibodies across age [33]. It is understandable that the levels of antibody do decrease over time since the last vaccination. Memory $\mathrm{T}$ cells are very important in maintaining the protective immunity and response to vaccination. It is stated that memory $\mathrm{T}$ cells generated from more aged naive $\mathrm{T}$ cells do survive and persist well in vivo but there are markedly defective in their proliferation and ability to secret cytokines during recall responses. On the contrary, memory $\mathrm{T}$ cells generated in younger individuals retain function for an extended period of time as their host ages [34]. Anyhow, both adult groups in our study still had long-term protective levels of anti-diphtheria antibody (above $1.0 \mathrm{IU} / \mathrm{mL}$ ) years after the primary immunization.

Re-vaccination after primary vaccination induced higher levels of anti-diphtheria antibody than primary vaccination alone. Older adults usually need more doses or schedules of vaccination to reach titers similar to those achieved in the younger group [35]. It proved 
not to be case in our study, as both young and middle-aged groups experienced a significant increase in anti-diphtheria antibody titers 3 months after vaccination. There was no significant difference between the two groups. These findings can be explained by the median value of the age of both groups, being 31 years in the young adult group and 46 years in the middle-aged adult group. Both of them were still below 50 years, and their thymus glands were considered as yet undergone complete involution [36, 37]. The increase in antidiphtheria antibody titers after vaccination in young and middle-aged adults in our study is consistent with the results of Grasse et al, who also reported increased antibody titer up to $93 \%$ after vaccination in young and older adults [38].

\section{Conclusion}

Diphtheria vaccination with the Jerap Td vaccine has been shown to significantly increase antibody titers in both young and middle-aged adult groups. Before vaccination, individuals in the middle-aged adult group had slightly lower (but non-significant) anti-diphtheria antibody titers (resulted from previous primary vaccination in the past). There were no significant differences in terms of post-vaccination antibody titers and the rise in antibody titers in both age groups, suggeting that the young and the middle-aged adults have an equal immune response to the particular diphtheria vaccine.

\section{Acknowledgment}

We would like to thank Fis Citra Ariyanto as our editor.

\section{References}

1. Amarya, S., K. Singh, and M. Sabharwal, Ageing Process and Physiological Changes, in Gerontology. 2018, IntechOpen.

2. Rodríguez-Rodero, S., et al., Aging genetics and aging. Aging and disease, 2011. 2(3): p. 186.

3. Aw, D., A.B. Silva, and D.B. Palmer, Immunosenescence: emerging challenges for an ageing population. Immunology, 2007. 120(4): p. 435-446.

4. Ma, Y. and M. Fang, Immunosenescence and age-related viral diseases. Science China Life Sciences, 2013. 56(5): p. 399-405.

5. Fulop, T., et al., Immunosenescence and Inflamm-Aging As Two Sides of the Same Coin: Friends or Foes? Frontiers in Immunology, 2018. 8(1960).

6. Goodwin, K., C. Viboud, and L. Simonsen, Antibody response to influenza vaccination in the elderly: A quantitative review. Vaccine, 2006. 24(8): p. 1159-1169.

7. Melegaro, A. and W.J. Edmunds, The 23-valent pneumococcal polysaccharide vaccine. Part I. Efficacy of PPV in the elderly: a comparison of meta-analyses. European journal of epidemiology, 2004. 19(4): p. 353-363.

8. Wolters, B., et al., Immunogenicity of combined hepatitis A and B vaccine in elderly persons. Vaccine, 2003. 21(25): p. 3623-3628.

9. Oxman, M., et al., A vaccine to prevent herpes zoster and postherpetic neuralgia in older adults. New England Journal of Medicine, 2005. 352(22): p. 2271-2284.

10. Martin, M., et al., Advanced age a risk factor for illness temporally associated with yellow fever vaccination. Emerging infectious diseases, 2001. 7(6): p. 945.

11. Fernandes, R., et al., Tetanus Immunity in Long-Term Care Facilities. Journal of the American Geriatrics Society, 2003. 51(8): p. 1116-1119.

12. Kaml, M., et al., Booster vaccination in the elderly: Their success depends on the vaccine type applied earlier in life as well as on pre-vaccination antibody titers. Vaccine, 2006. 24(47): p. 6808-6811. 
13. Weyand, C.M. and J.J. Goronzy, Aging of the immune system. Mechanisms and therapeutic targets. Annals of the American Thoracic Society, 2016. 13(Supplement 5): p. S422-S428.

14. Montecino-Rodriguez, E., B. Berent-Maoz, and K. Dorshkind, Causes, consequences, and reversal of immune system aging. The Journal of clinical investigation, 2013. 123(3): p. 958-965.

15. Martelli, S., S.L.F. Pender, and A. Larbi, Compartmentalization of immunosenescence: a deeper look at the mucosa. Biogerontology, 2016. 17(1): p. 159-176.

16. Sariadji, K. Indonesia's diphtheria outbreak: problems in vaccination and antibiotics efficacy. 2017; Available from: http://theconversation.com/indonesias-diphtheriaoutbreak-problems-in-vaccination-and-antibiotics-efficacy-89036.

17. Fadlyana, E., et al., Imunogenisitas dan keamanan vaksin tetanus difteri (Td) pada remaja sebagai salah satu upaya mencegah reemerging disease di Indonesia. Sari Pediatri, 2016. 15(3): p. 141-9.

18. Rachmita, I. Outbreak Response Immunization Difteri. 2017; Available from: https://www.kompasiana.com/intanrachmita/5a2e3068ab12ae59356ece03/outbreakresponse-immunization-difteri.

19. Völzke, H., et al., Susceptibility to diphtheria in adults: prevalence and relationship to gender and social variables. Clin Microbiol Infect, 2006. 12(10): p. 961-967.

20. Carson, P.J., et al., Immune Function and Vaccine Responses in Healthy Advanced Elderly Patients. Arch Intern Med, 2000. 160(13): p. 2017-2024.

21. Kumar, S., et al., Standardization and validation of Vero cell assay for potency estimation of diphtheria antitoxin serum. Biologicals, 2009. 37(5): p. 297-305.

22. Di Giovine, P., et al., External Quality Assessment for the Determination of Diphtheria Antitoxin in Human Serum. Clinical and Vaccine Immunology, 2010. 17(8): p. 12821290.

23. Gowin, E., et al., Does vaccination ensure protection? Assessing diphtheria and tetanus antibody levels in a population of healthy children: A cross-sectional study. Medicine, 2016. 95(49).

24. Hainz, U., et al., Insufficient protection for healthy elderly adults by tetanus and TBE vaccines. Vaccine, 2005. 23(25): p. 3232-3235.

25. Murphy, T.V., et al., Prevention of pertussis, tetanus, and diphtheria among pregnant and postpartum women and their infants recommendations of the Advisory Committee on Immunization Practices (ACIP). MMWR. Recommendations and reports: Morbidity and mortality weekly report. Recommendations and reports, 2008. 57(RR-4): p. 1-51.

26. Hakim, F.T., et al., Age-dependent incidence, time course, and consequences of thymic renewal in adults. The Journal of Clinical Investigation, 2005. 115(4): p. 930-939.

27. Kovaiou, R.D., D. Herndler-Brandstetter, and B. Grubeck-Loebenstein, Age-related changes in immunity: implications for vaccination in the elderly. Expert Reviews in Molecular Medicine, 2007. 9(3): p. 1-17.

28. Weiskopf, D., B. Weinberger, and B. Grubeck-Loebenstein, The aging of the immune system. Transplant International, 2009. 22(11): p. 1041-1050.

29. Weinberger, B., et al., Biology of Immune Responses to Vaccines in Elderly Persons. Clinical Infectious Diseases, 2008. 46(7): p. 1078-1084.

30. Boraschi, D. and P. Italiani, Immunosenescence and vaccine failure in the elderly: Strategies for improving response. Immunology Letters, 2014. 162(1, Part B): p. 346353.

31. Choi, J.-H., et al., Immunogenicity and safety of diphtheria-tetanus vaccine in adults. Journal of Korean medical science, 2010. 25(12): p. 1727-1732. 
32. Murhekar, M., Epidemiology of Diphtheria in India, 1996-2016: implications for prevention and control. The American Journal of Tropical Medicine and Hygiene, 2017. 97(2): p. 313-318.

33. Launay, O., et al., Antibodies to tetanus, diphtheria and pertussis among healthy adults vaccinated according to the French vaccination recommendations. Human vaccines, 2009. 5(5): p. 341-346.

34. Haynes, L., et al., CD4 T cell memory derived from young naive cells functions well into old age, but memory generated from aged naive cells functions poorly. Proceedings of the National Academy of Sciences, 2003. 100(25): p. 15053-15058.

35. Bayas, J., et al., Immunogenicity and reactogenicity of the adult tetanus-diphtheria vaccine. How many doses are necessary? Epidemiology \& Infection, 2001. 127(3): p. 451-460.

36. Mitchell, W.A., P.O. Lang, and R. Aspinall, Tracing thymic output in older individuals. Clinical \& Experimental Immunology, 2010. 161(3): p. 497-503.

37. Pido-Lopez, J., N. Imami, and R. Aspinall, Both age and gender affect thymic output: more recent thymic migrants in females than males as they age. Clinical \& Experimental Immunology, 2001. 125(3): p. 409-413.

38. Grasse, M., et al., Booster vaccination against tetanus and diphtheria: insufficient protection against diphtheria in young and elderly adults. Immunity \& Ageing, 2016. 13(1): p. 26. 